\title{
La llengua dels sermons valencians de sant Vicent Ferrer
}

\section{[The language of the Valencian sermons of Saint Vincent Ferrer]}

\author{
Jordi COLOMINA \\ Universitat d'Alacant, Acadèmia Valenciana de la Llengua \\ jordi.colomina@ua.es
}

Resum: En el present article es presenta un estudi lingüístic, en avançat estat d'elaboració, sobre la fonètica, la morfosintaxi, la morfologia lèxica, el lèxic i la fraseologia continguda en els vora tres-cents sermons vicentins valencians. Es mostra també l'interés dels sermons vicentins castellans, en algun cas usats com a font en l'elaboració de sermons valencians. S'oferixen com a mostra del futur Diccionari integral vicentí els articles corresponents a mà i a mal. ${ }^{2}$

PARAules Clau: Valencià-català, llengua medieval, lexicografia, sant Vicent Ferrer.

АвSTRAст: This article presents a linguistic study, in an advanced stage of elaboration, on phonetics, morphosyntax, lexical morphology, lexicon and the phraseology contained in the almost three hundred Valencian Vicentine sermons. The interest of the Castilian Vicentine sermons is also shown, which in some cases were used as a source in the elaboration of Valencian sermons. As a sample of the upcoming Vicentine Integral Dictionary, articles corresponding to mà and $m a l^{2}$ are offered.

KeYWords: Valencian-Catalan, medieval language, lexicography, Saint Vincent Ferrer.

Recepció: 26/02/20I9. Acceptació: 08/03/20I9. Publicació: 05/04/20I9

REVISTA VALENCIANA DE FILOLOGIA/II I (2OI9) p. IO3-I25/ISSN 0556-705X/DOI IO.28939/RVF.V3IO.6I 


\section{Els sermons vicentins valencians}

Contràriament al que s'esdevingué amb els sermonaris llatins de sant Vicent, publicats abundosament des del segle $\mathrm{xv}$, dissortadament els sermons vicentins valencians no han vist la llum fins al segle. Si bé Roc Chabàs (1903) i Henry D. Fages (1909) en publicaren diversos fragments, devem a Sanchis Sivera la transcripció dels dos grans sermonaris de l'Arxiu de la Seu de València. En 1927 ens oferí els 53 sermons del manuscrit 273, que conté la Quaresma predicada en València en 1413, i, en dos volums publicats en 1932 i 1934, 55 sermons del ms. 279. Els set sermons restants dels ms. 279, els 75 del ms. 278 i els 68 del ms. 276, que Sanchis Sivera havia transcrit en bona part i havia revisat R. Aramon (com ens informa Schib 1975: 7), no pogueren vore la llum per la guerra del 1936-1939 i per la mort de S. Sivera en 1937. Gret Schib en reprengué l'edició i culminà la publicació, entre 1975 i 1988, dels 205 sermons dels ms. 279-78-76. Dels sermons del ms. 277 (desaparegut durant la guerra de 193639) només se n'han publicat sencers 16 (dos per Sivera i 14 per Schib a partir de les transcripcions conservades de Sivera). A més dels 274 sermons vicentins valencians procedents de la Seu de València, se n'han publicat 14 més. En l'arxiu de l'arxiprestal de Morella es conservaven quatre manuscrits amb una desena de sermons vicentins (Perarnau 1999a: 19), dels quals només se n'han publicat dos, a cura de Manuel Betí (1922 i 1955). Feliu Mateu i Llopis (1959) va publicar un sermó vicentí sobre la predestinació predicat en València en 1410. Josep Perarnau ha publicat onze sermons vicentins, amb trets del català oriental, de la Biblioteca de Catalunya: set del ms. 477 (Perarnau 1974 i 1985) i quatre del ms. 476 (Perarnau 1996). En total disposem, doncs, de vora tres-cents sermons vicentins valencians, 288 en concret.

\section{Parers sobre la llengua dels sermons de sant Vicent Ferrer}

Vejam tot seguit, ordenats cronològicament, alguns comentaris sobre la vàlua lingüística dels sermons vicentins valencians. Manuel Betí (1922: 124),

REVISTA VALENCIANA DE FILOLOGIA / I I I (20I9) p. IO3-I 25 JORDI COLOMINA

La llengua dels sermons valencians de sant Vicent Ferrer / IO4 
editor del primer sermó vicentí valencià complet, lloava «su gracejo en el decir, en la frase popular y dicción corta, suave, graciosa e insinuante». Per al mallorquí Llorenç Riber (1924) la llengua de sant Vicent era «un català opulent, llibert i orejat, el català de les places públiques, el català dels camins i dels hostals». Per a Sanchis Sivera, en els sermons que es conserven en el nostre idioma, es manifesta la «vivesa expressiva de l'ànima de la llengua» (1927: LVI), «el llenguatge sovint no és polit ni correcte, però sí expressiu, pintoresc i insinuant» (I932: I 5), «la importància dels sermons de sant Vicent des del punt de vista filològic és tan gran, que els considerem com «el primer monument que es conserva en la nostra llengua [...]; el valencià parlat en temps de sant Vicent és el mateix que parlem ara; ningun idioma del món té semblant gloriosa prerrogativa» (1923: 23).

Martínez Ferrando (1952: 9 i 11) es feia ressò de les paraules d'Henry Gheon, que considerava els sermons vicentins «els més autèntics joiells que han pogut brollar de l'ànima i de la parla popular d'un país», però, coincidint amb Sanchis Sivera, ens mostra una visió poc positiva del seu «llenguatge cru, poc polit, àdhuc poc correcte, i de vegades groller». Fuster (1955: 165) també remarcava l' «especial interés filològic» dels sermonaris valencians de sant Vicent: «el testimoni més solvent que ens queda sobre la llengua tal com es parlava durant la darrera Edat Mitjana». Riquer (1964: 263) destaca «la plasticitat del llenguatge de sant Vicent i la seua espontaneitat, a la qual contribueix un cert desgavell sintàctic», "un llenguatge molt viu, amb el característic to del valencià popular».

\section{El valencià en els sermons vicentins llatins}

També oferixen abundoses frases en valencià els sermonaris llatins de sant Vicent. Per al nostre treball hem despullat els següents: el d'Aiora (Robles 1995), el del Col-legi Seminari del Corpus Christi de València (Gimeno \& Mandingorra 2002), el de Perusa (Gimeno \& Mandingorra 2006) i el de Friburg (Gimeno \& Mandingorra 2009); també hem aprofitat els fragments

REVISTA VALENCIANA DE FILOLOGIA / I I I (2OI9) p. IO3-I 25 JORDI COLOMINA La llengua dels sermons valencians de sant Vicent Ferrer / 105 
valencians dels quatre sermons llatins de la Biblioteca de Catalunya (Perarnau 1985 i 1989) i de les divisions esquemàtiques dels resums del valuosíssim inventari de Perarnau (1999).

\section{Els sermons vicentins occitans}

És molt interessant el magnífic sermó vicentí del Divendres Sant predicat íntegrament en occità a Tolosa en 1416 (Brunel 1953, Fornés 2010). Vet-ne ací l'inici:

AYSSÒ ÉS LO SERMÓ QUE FETZ LO REVERÉN MAESTRE VINCÈN EN LA CIOUTAT DE THOLOZA LO JORN DEL DIVENDRES SANHT MIEL CCCCXVI, ONT ÉS ENSERIDA TOTA LA SUBSTANSA DE LA PASSIÓ DE NOSTRE SENHOR JHESUCHRIST. Sermó del divendres saint de la passió de Nostre Senhor e Salvador Jhesuchrist. Thema: 'Expedit unum hominem mori pro populo'. Istud verbum habetur originaliter Jo. $X V I I I^{\circ}$ capitulo et recitatum est statim in Passione Domini. La beneyta sanhta e sagrada passiou de Nostre Senhor e Salvador Jhesuchrist differenment en diversas manieyras és representada al jorn d'uey en la Glieyga, e enayssí com los autres jorns aquesta sanhta passiou se representava coma en temps passat, que dizíam in illo tempore, que en aquel temps era enayschí estat, emperò al jorn d'uey per tot lo món en la Sancta Glieyga se recita ayschí com si era la causa prezén. E a ffi que los crestiàs ayan compassió e dolor a Nostre Senhor Jhesuchrist, quar las chauzas passadas no moven ponch lo cor a home d'aver compassiou ni dolor, enquera que om las li recomte, mas que diran: 'Bé me desplatz', e no ploraran ponch, mas las chauzas prezens esmoven lo cor a home d'aver compassió e dolor, e por so la Glieyga no comensa ponch huey coma de chauza passada in illo tempore, mas del jorn d'uey, egressus est etc., enayschí com de la chauza presén, e di que yschit és huey Jhesuchrist am los seus dessiples entrosque al torrén de Cedron. E a ffi que totz ayam alcuna compassió e dolor de Nostre Senhor e Salvador Jhesuchrist e de la beneyta Verges Maria mayre

REVISTA VALENCIANA DE FILOLOGIA / II I (20I9) p. IO3-I25

Jordi COLOMINA

La llengua dels sermons valencians de sant Vicent Ferrer / Io6 
soa, ministran en tribulació, parla enayschí coma de chauza prezén, e per so a home o fempna qui estay en dolor ni en tristícia no se aperté ponch que om li fassa deguna salutació gracioza. E com la Verges Maria glorioza fos al jorn d'uey en mot granda dolor e tristícia e turmén, pensan en la dolor del seu beneyte filh, per so no cové ponch que om li fassa la gracioza salutació acostumada, mas you, confermant me am la Sanhta Mayre Glieyga, vuelh servar la costuma. E per so car en tan gran sermó e matèria tant hauta e tant sanhta no és razó que estia ses adjutori, per so nos tornem doncas de bon cor al Crocific e que lo adorem devotamén, pensan que nos lo veyem de prezén crocificat, en dizent enayschí:

El fragment mostra, com podem comprovar, un magnífic occità comú de la primeria del segle $\mathrm{xv}$, amb alguns trets llemosins atribuïbles al reportador. Hem aprofitat a fons este sermó, predicat en una varietat de la nostra mateixa llengua, i que manca en la quaresma valenciana perquè el reportador es va emocionar tant que no va poder pendre'n notes: aquell dia 21 d'abril de 1413, «Die veneris Sancta non valui scribere sermonem propter fletum» ( «el Divendres Sant no vaig tindre força per a escriure el sermó a causa de les llàgrimes») Q 296.

\section{Els sermons vicentins castellans}

També són ben interessants els 35 sermons vicentins castellans publicats per P. M. Cátedra (1994). En algun cas es tracta de sermons que foren aprofitats per a redactar-ne altres en valencià, com és el cas del Sermón de las siete artes (Salamanca, 7/III/1412, pp. 303-322), aprofitat per a elaborar el Sermó de les set arts (Arxiu de la Seu de València, publicat per Sanchis Sivera (1934: 221-241). L'acarament entre les dos versions ens permet comprovar:

REVISTA VALENCIANA DE FILOLOGIA / I I I (20I9) p. IO3-I 25

JORDI COLOMINA

La llengua dels sermons valencians de sant Vicent Ferrer / I07 
a) com la versió valenciana és més breu que la castellana;

«Esso mismo, contenpla que assí como va «Ítem, contempla que axí com la luna no ha la luna, así va la Igleia; e contempla que assí lum de si, sinó per lo sol, axí l’Església, que como la luna non ha luz de sí misma sinon és comparada a la luna, que no lluu de si porque la rresçibe del sol, assí la Igleia non sinó per lo sol, qui és Jesuchrist, 'quia luna luçiria sinon por el sol eternal Jhesuchristo; quasi lux aliena', e luu per Jesuchrist, com e ves aquí actoridad: 'quia luna quasi lux la luna, per ses condicions que ha, axí com alliena'; diz que la Igleia luze por Jhesuc- la luna nova, crexent, minvant, retornada, hristo, assí como la luna luze por el sol; e eclipsada e perfeta; estes condicions ha la assí como la luna ha siete condiçiones, que Església» B 240

primeramente es nueva e después cresçiente e después llena e después menguante, e después rretornada e después clisida e después perfeta, agora yo digo que estas mismas condiçiones ha avido la Igleia» $\mathrm{Ca} 321$

b) la coexistència en les dos llengues de la locució ni grat ni gràcies, usada també en el Tirant (oblidada pels nostres repertoris lexicogràfics), i ni grado ni gracias, usada també en el Quixot;

«E que agora demos d•ello rrazón, nin grado «Ara sí, bé la dirà algú, mas ni grat ni grànin gracias» Ca 304. cies» B 223.

c) l'equivalència de l'adverbi antic ivarç, el castellà aýna, documentat en valencià a la primeria del segle XVI (Consells y bons avisos dirigits a una noble senyora valenciana novament casada, d'Andreu M. Pineda) usat encara a l'hora d'ara en valencià;

\begin{tabular}{l|l|}
\hline $\begin{array}{l}\text { «E cómo lo fallaste tan aýna, fijo?» } \\
\text { Ca } 306 .\end{array}$ & «Com has trobada tan ivaç caça? » B 225. \\
\hline
\end{tabular}

d) les correspondències entre cuytós i coydadoso i entre raxa i quexa;

REVISTA VALENCIANA DE FILOLOGIA / I I I (20I9) p. I03-I25

JoRdi COLOMINA

La llengua dels sermons valencians de sant Vicent Ferrer / 108 
"Nichil soliciti sitis [...]; diz: 'Non seades «Nichil solliciti sitis [...]; diu que no siau coydadosos nin ayades grant quexa, ca si queredes aver don de Dios, demandat con postulación e con oración e con obsecración cuytosos ni hajau raxa, si voleu haver dons de Déu, mas demanau ab oració e obsecrae con gratiarum acçión» Ca 311.

e) l'alternança entre l'antic i occità ço que i el modern i hispànic lo que;

\begin{tabular}{|l|l|}
\hline $\begin{array}{l}\text { "Que es aquello que avemos a creer; la se- } \\
\text { gunda manera es contra la buena vida, que } \\
\text { es lo que avemos a fazer» Ca ço que havem a creure; la sego- }\end{array}$ & $\begin{array}{l}\text { na disputa contra la vida, que és lo que hom } \\
\text { ha a fer» B 227. }\end{array}$ \\
\hline
\end{tabular}

\section{f) la correspondència entre per a que i para que;}

«Avrá mester çinqüenta años para que la «Haurà mester $\mathrm{x}$ anys per a que sàpia bé sepa bien specular» Ca 305. specular» B 224.

g) l'ús de millons (en comptes de milions, usat per Antoni Canals) i la traducció lliure de de ssisse per d'ací;

\begin{tabular}{|l|l|}
\hline «Ca un pobrezillo non da cuenta sinon de & "Axí matex del rey, que hun simple home \\
ssisse, e darla ha en un punto, mas papa o & pobrellet d'ací, allí ha donat son compte a \\
rrey o obispo, ¡o, qué cuenta tan estrecha les & Jesuchrist, mas rey o compte, de si e de mil \\
será demandada, que han de dar cuenta de si & mília millons de ànimes» B 238. \\
e de mill millones de ánimas!» Ca 319. & \\
\hline
\end{tabular}

b) l'ús de la locució pendre en mentira com a equivalent a tomar en mentira;

\begin{tabular}{|l|l|}
\hline $\begin{array}{l}\text { «O, ssi el confessor fuesse avisado, cómo le } \\
\text { tomaría lugo en mentira! Si dixiesse:» } \\
\text { Ca } 316 .\end{array}$ & $\begin{array}{l}\text { E guarda que si lo confessor és savi, com lo } \\
\text { pendra en mentira, que li diga:» } 235 .\end{array}$ \\
\hline
\end{tabular}

REVISTA VALENCIANA DE FILOLOGIA / I I I (2OI9) p. IO3-I 25

Jordi Colomina

La llengua dels sermons valencians de sant Vicent Ferrer / Io9 
i) l'ús de sombra (també present en el Curial) només en este sermó, enfront d'una vintena d'aparicions d'ombra en els altres sermons;

«E faziendo esta oraçión, vino súbitament una grant sombra que le dio un tal golpe en la cara que le fizo caer en tierra amorteçido" Ca 311.
«Estant axí, vingué súbitament una sombra que li donà un colp que 1 gità en terra mig mort» B 230.

j) un lapus en la traducció de soldán, que es convertix en soldada (si qui servix a un soldà és lògic que n'espere algun guardó, qui servix a soldada ja es pot ben aconformar amb la paga);

«E con todo esto, Señor, non he avido consolaçión alguna nin dulçor spiritual de vos; pues si al soldán oviera yo servido, non puede ser que d·él non oviera yo avido algún galardón; e de vos, Señor, nunca he avido nada» Ca 311.

k) un curiós ús del verb baciar-se 'buidar-se', induït per les aparicions de vazía en el sermó castellà. En la llengua actual són vius en el lèxic ramader l'adjectiu baciu -iva 'que no cria, que no és apte per a la cria' i bacivar 'passar sense criar' $(A l c M)$; i en occità antic hi havia el substantiu ramader vaciu 'antenois, mouton dans sa deuxième année' (PDPF);

«Buena gente, bien sabedes que guitarra es madero seco e vano de dentro; assí la persona torna seca e vazía por penitencia; esto es, que la tal persona siempre anda desmayada e seca e vazía de dentro; esto es, que en el su coraçón non está malicia nin mal deseo» Ca 313. 
i l) la demostració palpable de la traducció: el copiste va deixar en castellà la forma verbal suene.

\begin{tabular}{|l|l|}
\hline «i ánima, que moras en los huertos -esto & «iO ànima, que estàs en los orts -ço és, en la \\
es a saber, en la Ygleia christiana-, faz que tu & Església christiana-, fes que la tua veu -esta \\
voz -es a saber, la que dicha he- suene a las & que dit he- suene a les mies orelles, que bé \\
mis orejas, que bien te ascuchan!’» Ca 325. & t'escolten les mies orelles!’» B 234.
\end{tabular}

\section{Estudis sobre la llengua dels sermons vicentins}

Malgrat uns comentaris tan elogiosos com els que hem mostrat adés, són escadussers els treballs dedicats a l'anàlisi lingüística del sermons vicentins valencians. Si Sanchis Guarner (1973: 28-32 i 1980: 203-210) ens va oferir unes breus notes sobre la llengua dels sermons, només dos autors s'han ocupat a fons de la llengua dels sermons: Gret Schib (1977) ens oferí l'estudi més complet publicat fins ara del lèxic vicentí, i Emili Casanova (2008) ha descrit els principals trets morfosintàctics i el lèxic de les dos col-leccions de sermons de la Seu de València. Isern (2010: 272) ha assenyalat, en una excel-lent síntesi dels estudis vicentins, «la necessitat de disposar d'unes bones concordances lèxiques lematitzades».

\section{Un tast del nostre treball}

El nostre treball, en estat avançat de redacció, La llengua dels sermons valencians de sant Vicent Ferrer, complementa els estudis de Schib i Casanova i tracta de cobrir el buit assenyalat per Isern, car es proposa elaborar un estudi lingüístic exhaustiu de la fonètica, la morfosintaxi, la morfologia lèxica, el lèxic i la fraseologia continguda en els vora tres-cents sermons vicentins valencians. Per tal de mostrar l'interés del nostre estudi compararem tot seguit el contingut d'una de les 265 pàgines del vocabulari de Schib (1977) amb la nostra apor-

REVISTA VALENCIANA DE FILOLOGIA / I I I (20I9) p. IO3-I 25

JORDI COLOMINA

La llengua dels sermons valencians de sant Vicent Ferrer / I I I 
tació lexicogràfica. Hem triat a l'atzar la pàgina 95 del llibre de Schib. Conté els 12 primers articles de la lletra M: maça, maçana, maceta, macipa, madrina, magrana, maisó, mal de sent Johan, mal de caure, mala, malastruc i malgrat. El nostre treball permet quintuplicar el material lèxic de Schib: a més dels seus 12 articles, nosaltres n'incorporem 48 més: ma, mà, maçaneta, màcula, maculós, madona, madrilleta, madur, madurar, maestre, magestat, magistral, magnificació, magnificar, magnificència, magnitud, magre, maig, major, majordom, majorment, mal $^{1}$ (adj.), mal (adv.), malacostumat, malair, malaït, malalt, malaltia, malaltiç, malaventura, malaventurat, malbarat, malcogitar, malcomprar, malcriament, maldir, maldispost, malea, maledicció, malencolia, malencoliós, malencoria, malesa, maleyt, malfactor, malfaytor, malfeytor.

Donem com a mostra dos articles del nostre Diccionari integral vicentí (DIV): els substantius mà i mal. ${ }^{2}$

MÀ

1. $f$. ANAT. Part terminal del braÇ, Dividida EN Dits PER a la prensió i sosteniment D'OBJectes. «Puys, en l'altre dia, l'altre nuu; puys l'altre dit; puys la mà, e axí de nuu a nuu los tallaran» Ml 131; "axí com havem en les mans deu dits a fer obres, axí havem deu manaments a regir e obrar per la ànima» Q 43.

ab les mans altes al cel "Que digats ab les mans altes al cel, genolls ficats en terra, una oració a l'àngel propri que vos té en custòdia» D 79.

ab les mans juntes "Di Pater noster agenollat e ab les mans juntes» A 19; "quan lo prevere se met davant l'altar fins al mig, ab les mans juntes» B 252.

ab les mans llavades «Tots quants vinguen demà a dinar ab les mans lavades, yo li daré a dinar» A 100.

mans e peus «Vet ací les mies mans e los meus peus» E 103.

ajustar les mans "Per lo matí, ans, que isqués de casa, yo fiu oració agenollat en terra; ajustant les mans e llevant la pensa en Déu, fiu ma oració» A 60; «de-

REVISTA VALENCIANA DE FILOLOGIA / II I (20I9) p. IO3-I25

Jordi COLOMINA

La llengua dels sermons valencians de sant Vicent Ferrer / I I 2 
veu-los instruir que, per lo matí, que fermen los genols en terra, e que ajusten les mans pregant en alt» $\mathrm{Pa} 636$.

dur mans lligades «Fo pres per los malvats juheus e duyt mans lligades davant Cayphàs e altres rabins» $\mathrm{B} 265$.

estendre les mans «Quan los pobres vindrien, alçarien los huylls e estendrien les mans» A 23-24;

levar la mà «E tantost él vay levar la ma e vay-li donar de tot son poder tan granda una gautada [de tot son poder] que él lo vay far tombar en terra» $\mathrm{Br} 31$. menar per la mà «Te mena per la mà» Q 4.

metre la mà en les mamelles "Començà'l a toquar, e li dix que li metés la mà en les mamelles, e ella lo volgué besar» Q 17.

pendre la mà «Mostrar-li-ha com ballen prenent-li la mà; axí que no·ls amostren sinó de fer vanitats e·l camí de l'infern» $\mathrm{Pa} 637$.

pendre per la mà «Ell lo pren per la mà e mena'l lla on era Jesuchrist» G 182; «pendrà-la per la mà [a la Verge Maria] e dirà als àngels:» G 272.

posar les mans sobre "Posarets les mans sobre los malauts e seran de continent gorits e sanats» Pc 299.

sullar-se les mans «item nostrum est mundum valde, car ja vets aquella forma petita quant és bella e blancha, et vinum purum, et corporalia alba, no s'i sullen les mans» Ai 109.

tenir en la mà «Hun dia mes-se a legir de la sancta Trinitat, e ell fon arrapat que una candela que tenia en la mà li cremava ja la mà, que no sentia res» Q 17; «tenia huna carteta en la mà» Q 15.

venir en la mà de «La almoyna hix de la mà tua e ve en la mà del pobre» C 283.

2. MÀ DRETA loc. subst. LLOC COSTAT DRET D'UNA COSA EN RELACIÓ AL QUI LA MIRA O AL QUI EN FORMA PART.

a la man dreta «E deçà a la man dreta és altre camí, montanyós, aspre, etc.» G 42 .

REVISTA VALENCIANA DE FILOLOGIA / I I I (2OI9) p. IO3-I 25

JORDi COLOMINA

La llengua dels sermons valencians de sant Vicent Ferrer / I I 3 
de mà dreta "Gran mentida dieu; car aqueix cami a infern va, mas preniu l'altre camí de mà dreta» Fm 151.

3. MÀ EÇQUERRA loc. subst. LLOC COSTAT ESQUERRE D'UNA COSA EN RELACIÓ AL QUI LA MIRA O AL QUI EN FORMA PART.

en la mà eçquerra «Bé sabeu que.l crucificar de Jesuchrist fo principalment en v plagues: en la mà dreta, puix en la mà eçquerra, etc.» C 264.

de mà esquerra "partint de Saragoça per anar en altra terra, ha·y dos camins: lo baix de mà eçquerra és pla e plaent, ple de tavernes, e deça e de lla arbres, donzells, rossinyols, regadius e putanes per los ostals» G 174 .

4. MÀ SINESTRA loc. subst. LLOC COSTAT ESQUERRE D'UNA COSA EN RELACIÓ AL QUI LA MIRA O AL QUI EN FORMA PART.

de la mà sinestra «E la ciutat ha fet una torre en la qual està una bada, que veu abduy los camins, e avisa les gents que vagen per aquell camí de la mà sinestra, que tot és lladres» Fm 150.

5. MÀ SINISTRA loc. subst. LLOC COSTAT ESQUERRE D'UNA COSA EN RELACIÓ AL QUI LA MIRA O AL QUI EN FORMA PART.

en la mà sinistra «Fet la caxa miganada, e los diners bons metet-los en la part dreta, e los mals diners en la mà sinistra» C 265.

sinistra mà "Jesuchrist nos diu que sia secreta l'aymoyna [sic], que la sinistra mà no•u sàpia lo que fa la dreta, e Nostre Senyor Déu te darà remuneració complida» Q 35.

6. A LA MÀ d'algú loc. prep. PODER A LA DECISIÓ, EN PODER DE. «Tot ho coman a la mà de Deu» Q 188.

7. De MANS de loc prep. Del PODER De.

deslliurar de mans de "Desliurar-vos ha de mans dels philisteus, ço és, de tot caÿment e de tota roÿna [...] de pecats e de vicis mortals e capitalls» Pc 316.

8a. DE mans loc adj. TREBALL Manual, Fet amb les mans.

fer obres de mans «Fahye açtores e obres de mans, e venie-les» E 24.

REVISTA VALENCIANA DE FILOLOGIA / I I I (2OI9) p. IO3-I 25

Jordi COLOMINA

La llengua dels sermons valencians de sant Vicent Ferrer / I I 4 
8b. DE Ses mans loc adj. TREBALL Manual, FET AMb Les MANS.

obres e treballs de nostres mans «Est infant nos consolarà de les obres e treballs de nostres mans en la terra, la qual Déu ha malahit» Q 13.

8c. DE SES MANS loc. $a d v$. TREBALL CONSEguINT-HO AMB EL PROPI ESFORÇ, AMB EL TREBALL PROPI.

donar vida de ses mans "Depuix, com a esterrada anà en Egipte ab Joseph, qui ere vell e fuster, que no podie ja fer fahena; mas la Verge Maria vii anys donà vida a ella e a Joseph e a son fill de ses mans, que sabia texir» C 76.

viure de ses mans «Mas vivie de ses mans» C 197.

8d. ObRAR DE MANS loc. verb. TREBALL REALIZAR TREBAlls o ACTIVITATS MANUALS. "Car no obrava de mans, ¿què feya?» Q 44; "si obrave de mans o si estave ociós» E 131; «santa cosa és obrar de mans» Q 325.

8e. ObRAR DE SES MANS loc. verb. TREBALL REALIZAR TREBAlls o ACTIVITATS MANUALS. "Car la soa beneyta mayre la avia facha [la vistidura] a manieyra d'un bierret ses costura, am ponch d'agulha, car la beneyta dona sabia mot subtielmen obrar de sas mas» $\mathrm{Br} 43$; «obrat de vostres mans, filar, etc.» G 134. 8f. TREBALLAR DE SES MANS loc. verb. TREBALL REALIZAR TREBALLS O ACTIVITATS MANUALS. "A exemple de la verge Maria, que trebàllon de ses mans» D 276.

9a. PER MÀ d'algú loc prep. TREBALL MitJANÇANT LA SEUA FAENA, GRÀCIES A LA SEUA PARTICIPACIÓ.

fet per mà de «L'archa ere feta per mà de fusters» G 197.

haver per mà de «Degú no pot haver cambra sinó per mà de la putana» G 90; «los fills no podien haver pa ne res sinó per mà de la esclava» F 108; "sinó per mà de Déu»Q 160.

9b. PER LA MÀ d'algú loc prep. TREBALL MitJANÇANT LA SEUA FAENA, GRÀCIES A LA SEUA PARTICIPACIÓ.

trametre per la mà de «Féts almoyna; trametets-o dellà per la mà dels pobres, que és taula segura»D 231.

REVISTA VALENCIANA DE FILOLOGIA / I I I (20I9) p. IO3-I 25

JORDi COLOMINA

La llengua dels sermons valencians de sant Vicent Ferrer / I I 5 
venir per la mà de «Tots [los affanys] venen per la mà de Déu» G 152.

9c. PER MANS d'algú loc prep. TREBALL MitjanÇANT LA SEUA FAENA, GRÀCIES A LA SEUA PARTICIPACIÓ.

per mans de «E menjaren del cors preciós de Jhesucrist a Paschua, per mans del prevere» Q 47; «per mans de cristians morí en tal dia com huy» G 226.

fet per mans de "Adorem pa que és fet per mans de hòmens?" G 197.

9d. Per les mans d'algú loc prep. TREBALL Mitjançant la Seua faena, gràCIES A LA SEUA PARTICIPACIÓ.

per les mans de "Natura, per les mans de la qual a nosaltres cové de haver pa e vi e les altres coses terrenals» F 108.

10a. MÀ A ma $l o c$. $a d v$. AgAfANT-SE MÚtUAMENT LeS MANS. «No hauran mester que l'àngel los aport, mas mà a mà̀ G 278 .

10b. MÀ PER MÀ loc. $a d v$. AgAfAnT-Se mútUAMENT Les MANS. «E lavòs jaquí les lances, e mà per mà tornaren-se'n al cell ensemps ab la Verge Maria» Pc 273.

man per mà «Dita la missa, lo clérigo havie consagrades moltes òsties e venen los hòmens de dos en dos, man per mà e combreguen e aprés donen-se pau» G 47; "Jesuchrist se'n tornava a paraís ab sent Johan, man per mà, anant per les places de paraís» G 208; "Jesuchrist e la sua mare beneyta en mig, man per mà» A 44; "veus aquí la Verge Maria ab son fill man per mà» G 133.

11. De mà en mà $l o c$. $a d v$. Directament De les mans D'Uns i D'Altres. "Quant tots foren sadolls, dixit Iesus apostolis: 'Ite, et colligite que superaverunt fracmenta, ne pereant'; et apostoli vadunt ben sobraçats discurrendo per gentem et colligendo de mà en mà» Ai 77.

12a. Caure en mà d'algú loc. verb. PODER Anar a PARAR EN PODER SEU. «No és degú que, quan naix, no caygue en mà de l'àngel» $\mathrm{D} 72$.

12a. CaURe en les mans d'algú loc. verb. PODER Anar a parar en poder seu. «Ans de totes coses la creatura cau en les mans de l'àngel, ans que en les mans

REVISTA VALENCIANA DE FILOLOGIA / II I (20I9) p. IO3-I25

JoRdi COLOMINA

La llengua dels sermons valencians de sant Vicent Ferrer / I I 6 
de la paridera, per presta que sie, e té-la en sa guarda per manament de Déu fins a la mort» D 73.

13a. DONAR EN MANs d'algú loc. verb. PODER ANAR A PARAR EN PODER SEU. «E depuix, tenint son camí, dóna en mans de altres ladres» C 233.

13a. DONAR EN LES MANS d'algú loc. verb. PODER ANAR A PARAR EN PODER SEU. «Donà la sua ànima en les mans dels àngels» D 257.

14. LAVAR-SE'N LES MANS loc. verb. RESPONS. DeClaraR-SE NO RESPONSABle D'Alguna COSA. "Yo me'n lavi las mas, car aquest és just e sant e innocent» $\mathrm{Br}$ 37; «les mans me'n lau» Ai 77.

15. METRE LA MÀ a una activitat loc. verb. FAENA APLICAR-S'HI, POSAR-SE A FER-LA.

metre la mà a l'aradre "Car Jhesuchrist dix: (Luce, ix. ${ }^{\circ}$ c. ${ }^{\circ}$ ) "Nenguna persona que met la mà a l'aladre per laurar, si·s gira derrere, no és apte de entrar en lo regne celestial” "Q 324; "¿Què vol dir metre la mà a l'aradre?» D 61.

16. METRE MÀ en un lloc a on hi ha coses de valor loc. verb. FICAR-LA PER A AGAFAR-NE.

metre mà en la bossa "Hun dia passà una dona ab hun paner de leytugues fresques per vendre-les, e la dona de la pedra mes mà en la bossa e no·y trobe diners; dix la venedora: “Tant amaré la pedra”, e donà-la-li» G 252.

17. OBRIR-LI LA MÀ a algú loc. verb. AJUDA Mostra-s'Hi GENERós, ESPLÈndid. «O, si volien obrir la mà al pobre!» G 240; «diu que la persona misericordiosa obre la mà al freturós» G 230.

18. PARAR LeS mans loc. verb. ESTENDRE LES MANS AMb LES PALMES CAP AMUNT PER A ARREPLEgAR ALgunA COSA QUE S'HA DEMANAT. "E parà axí les mans Jesuchrist e pres la sua ànima, e axí la se’n pujà, e ve-la-us en paraís» G 189.

19. TENIR LA MÀ FORADAda loc. verb. DESPESA GASTAR SENSE RESTRICCIONS, SER MALGASTADOR. "Aquí devem fer hun forat, no tenir-la tanquada per avarícia, mas fer hun forat de misericòrdia, fent almoyna; e poràs dir: "Senyor, yo tinch la mà foradada per vos” »C 264.

REVISTA VALENCIANA DE FILOLOGIA / I I I (20I9) p. IO3-I 25 JORDi COLOMINA

La llengua dels sermons valencians de sant Vicent Ferrer / I I7 
20. TENIR MÀ en alguna cosa loc. verb. PODER TINDRE-Hi InfluènCIA, TINDRE-HI PODER. "Contra algunes males fembres que secretament faran son peccat, e per no ésser descubert<e>s, mataran lo prenyat [...] Quarto, contra aquells que·y tenen mà: metges, speciés; per ço avisau-vos que no·y entenats en affollar, que si no, en infern pregon irets» E 250.

DER.: manejar, maneta, manilla, manoll.

$\mathrm{MAL}^{2}$

1. $m$. DANY Dany MATERIAl o MORAL, DETRIMENT, PERJuí O MOLÈSTIA CAUSADA A ALGÚ EN ELS SEUS INTERESSOS, LA SEUA SALUT O EL SEU ESTAT. "Mas posau-hi vós aquest càrrech de estar tots temps en la ira de Déu en foch: més valrie ésser no res; e vet com no ésser res és mal, e ésser dapnat és lo major mal del món» E 247; «Serà lo mal de alscuns religiosos que seran lavors vells: “¡O mesquí, o malastruch, que he perdut món jovent! e ¿per què no venie açò al temps qui era jove?" " Ml 134; "vol dir aytant que nostre senyor Déus que no permetria mal, si ell no fos bastant a traure'n» F 35.

mal de culpa «Verbigràcia, dels mals de culpa: ¿per què Déu permeté que Adam pecàs ab Eva? Açò permeté per lo bé que·n devia exir; e per ço que·l seu fill prengués la nostra humanitat» F 35.

ésser inclinat a mal "E si fas qualque mal, dien los àngels a Déu: "Senyor, no prengats venjança de tal persona que ha peccat, car són inclinats a mal» D 76.

haver mal «E mordien-los serps, e morien, Déu dix a Moysés: fes huna serp d'aram, e travesa-la sobre hun pal, e qui·y guardarà, no haurà mal, et sic fuit» Q 74.

haver-ne mal "Ell donà comiat al fill del juheu, e la muller no n’hagué mal alcú» Ml 136.

rebre mal «Car si dormien defora, porien rebre qualque mal» B 129.

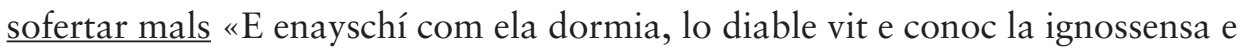
la sanhtetat de Jhesuchrist e la passiensa que avia a suffertar totz aquels mals» Br 34.

REVISTA VALENCIANA DE FILOLOGIA / I I I (20I9) p. IO3-I 25

JORDI COLOMINA

La llengua dels sermons valencians de sant Vicent Ferrer / I I 8 
venir-li mal «Tu, Jherusalem, no sabes ponch lo mal qui t'és a venir, car si tu lo saubessas, tu te'n plorarias»» $\mathrm{Br} 21$.

2. m. PAT. Dolor, PATIMENT FÍsic, MaLaltia.

tenir mal en l'ull «Ere hun metge en Castella, e guarie les gens de mal dels talons ab ceba; vench-y hun hom que tenie mal en l'uyll, ell li pose de la ceba, e va'l-li traure» G 22.

haver mal d'ulls «Se arreà com a gran metege [...] per continuar llur metgia, e a aquells que havien mal de huylls posave'ls-hi ceba (he, que solaç!) e matave'ls» C 181.

haver mal de pols «Haveu mal de pols? "Hoc". Açò vos ve per les polseres» G 216. haver mal al taló "Com ne pres a un rústich laurador, lo quall havia mal al taló, e anà-se'n a un metge, que li faés alguna medicina» Pq 221-2;

haver mal en la mà «E lo leó alçà la sua mà, a denotar que ell venie ab la mà uberta, que.y havie mal, ço és cranch» D 86.

guarir de mal dels talons «Ere hun metge en Castella, e guarie les gens de mal dels talons ab ceba; vench-y hun hom que tenie mal en l'uyll, ell li pose de la ceba, e va'l-li traure» G 22 .

venir mal de ventrell «Si ve mal de ventrell, dolor de cap» Q 194.

3. Fer mal loc. verb. DANY Provocar dany, Desgràcies. «E si fas qualque mal, dien los àngels a Déu: "Senyor, no prengats venjança de tal persona que ha peccat, car són inclinats a mal» D 76; «ans que haje acabada la letania, la núvol se destroirà, e la pedra caurà en terra, que no farà mal» $\mathrm{C} 306$; «dient que lo jorn del dejuni manat no cal dejunar, car massa és stret, o que lo dia de la festa podem fer faena e los lexia [sic] la regna a fer mal» $\mathrm{Pa}$ 631; «e per ço fan gran mal aquells qui meten mal ne divís en negun matrimoni, axí com alcavots o altres, qui destorben matrimonis per qualsevol altra manera, o alcavotes» $\mathrm{Pq}$ 173; «la nit signifique peccat, e ja, si degú vol fer mal, de nit lo fa» F 12; «una porta caygué e donà sobre tota la gent, e no feu mal més que una palleta» $\mathrm{G}$ 7; «si un hom és predestinat, aquella predestinació no tira lo franch arbitre, car ell

REVISTA VALENCIANA DE FILOLOGIA / I I I (2OI9) p. IO3-I 25 JORDi COLOMINA

La llengua dels sermons valencians de sant Vicent Ferrer / I I9 
pot fer bé o mal» Fm 149; "no fas [jo] mal ne tració [sic] a Déu, ne fas contra Déu»Pq 167.

4. FER MAL a algú loc. verb. DANY CAUSAR-LI DOLOR FÍsIC. "Allavors, si tots los hòmens li donaven ab les spases, sol no.l porien destorbar ni fer mal» $\mathrm{F}$ 25; "la cinquena màcula és de gola e voracitat: fa mal al cors e a la ànima per la vista e l'alé, tap de barral»Q 321-2; «los leons no.l gosaren toquar ni fer-li degun mal» D 220-221; "Axí com si ton enemich te tenia la lança als pits, e no hagués paor de fer-te mal, si donchs tu no la't meties» Ai 67; "gran mal, sa disch ela, me fay al cor» $\mathrm{Br} 39$; "mas dien molts que "' $\mathrm{m}$ fa mal aquest pecat de luxúria, mas no puch sobrar la voluntat”»Pa 639.

5. FER MAL a algú una part del cos. FISIOL. SENTIR-HI DOLOR. fer-li mal l'ull «Fabie-li mal l'uyll» D 40.

fer-li mal lo cap «E dien que.ls fa mal lo cap» E 59; "Altres escusant-se que.ls fa mal lo cap» E 237; "¿fa-us mal lo cap?» G 216.

6. FER MAL un aliment a algú loc. verb. FISIOL. No PROVAR-LI, NO DIGERIR-LO BÉ. "Si no·y bech, fer-m'a mal, e si bech sens menjar...»Q $\mathrm{Q} 8$; «e si vos deÿu: “Lo dejuni me fa mal”, més mèrit ne haveu» E 118; "lo ben mengar fa mal al vendre»C 184.

fer-li mal lo vi «Mas bevie vi, e per poch que·n begués li fahye mal (tal defalliment havie natural)» B 119.

7. mal de BURÇ PAT. Pleuritis, malaltia Que CAUSA un DOlor lancinant al COSTAT. «Et tamen non poterat curare se de mal de burch ut humiliaretur» Cc 145.

8. MAL DE CÀNCER PAT. TuMOR DE CARÀCTER MALIGNE I PERTORBADOR DE LES FUNCIONS BIOLÒGIQUES NORMALS, QUE COMPRIMIX ELS TEIXITS ORGÀNICS ADJACENTS I ELS ENVAÏX. " "Ha·y deguna dona que entre les mameles [sic] li sie fet mal de càncer o foch de sent Anthoni?”. "Hoc”. ¡Hee, mostrat les mamelles als milans!»G 216.

9. mal de CAURE PAT. Epilèpsia, malaltia CEREbral CARACTERitzada Per ATACS O CRISIS, SOBTATS I BREUS, AMB PÈRDUA BRUSCA DEL CONEIXEMENT I

REVISTA VALENCIANA DE FILOLOGIA / II I (20I9) p. IO3-I 25 Jordi COLOMINA

La llengua dels sermons valencians de sant Vicent Ferrer / I 20 
AMB CONVULSIONS. "E per ço han tantes malalties, puagres, mal de caure, etc.» E 148; "e venen-ne tants de mals, mal de caure, mal de sent Johan» A 271; «ítem, perden la força, que fa tremolar, e fa perdre l'enteniment, e fa venir poagre e mal de caure» Q 321; «si algú de vosaltres ha mal de caure o altra malaltia, e·l cap posat la creu, de la vayvella fins al nas, e digats "Jesús" $\mathrm{C}$ 303; «istud peccatum [...] dat podagra et mal de caure» Ai 385.

10. MAL De MORENes loc. subs. PAT. VARicositat Dels Plexes Venosos De LA PARET DEL CANAL ANAL O DEL RECTE. «Ítem, guarden la fi, si.n deu guarir, car hun hom que té scorredor en la cama, curant-ho serie pijor; ítem, si ha mal de morenes o de fluix de sanch, be porien guarir, mas serie perillós» Q 291.

11. MAL de SENT Joan PAT. Apoplexia, suspensió sobtosa de Les funcions CEREBRALS, AMB INTEGRITAT DE LA CIRCULACIÓ I DE LA RESPIRACIÓ. «E venen-ne tants de mals, mal de caure, mal de sent Johan» A 271.

12. MeriR-Hi MAL loc. verb. DANY MeréIXer PATIR Un MAL. "YO no·y mer mal, perquè aquest frare entrà en vila sens licència e begué en una casa sens que no•s senyà, e yo estava com a moscalló en lo vi”" G 168; «dix lo dyable: "Yo no·y mer mal, perquè aquest frare entrà en vila sens licència e begué en una casa sens que no·s senyà, e yo estava com a moscalló en lo vi” " G 168; "quan hun cavaller fa traÿció, encara que los fills no·y meren mal, mas tots temps diran:» C 202; «si Adam pecquà, ¿quiny mal hi meren los fills?» C 201.

13. mesclar mal loc. verb. Posar malvolença entre dos o més persones, PROMOURE-HI DISCÒRDIA. "Cascú se deu gardar de semblant pecat de blasphèmia, e mesclar mal, e sembrar zizània, oy, ira e rancor en sos proÿsmes» Pq 168.

14. metre mal loc. verb. Posar malvolença entre dos o més persones, PROMOURE-HI DISCÒRDIA. «E per ço fan gran mal aquells qui meten mal ne divís en negun matrimoni, axí com alcavots o altres, qui destorben matrimonis per qualsevol altra manera, o alcavotes» Pq 173.

15. PENDRe mal loc. verb. DANY PATIR Un DANY EN un ACCIDENT. "Quant fo ab sa muller, ell li dix: "senyora, yo-us assegur que no pendreu mal si vos me dehiu veritat, ¿aquest, sí és mon fill?”» Ml 136; "[diu el llop als cans:] "Ara

REVISTA VALENCIANA DE FILOLOGIA / I I I (2OI9) p. IO3-I 25 JORDi COLOMINA

La llengua dels sermons valencians de sant Vicent Ferrer / I 2 I 
les gens vos governen per amor de nosaltres, e des que hajau mort a nosaltres, no·us governaran, e axí·us morreu de fam; e axí consellar-vos hia que·us ne tornàsseu"; e tots acordaren que més valia, e almenys que no morrien de fam, e los lops no prengueren mal» F 51; «llavors Jesuchrist, vehent que era costret, jatsefós que sabés que mal li’n pendrie, volgué dar honor al nom de Déu» B 265.

16. RETRE MAL PER BÉ loc. verb. DANY CAUSAR DANY A QUI ENS HA FET UN BÉ. «E lo traÿdor, per bé, reté mal [...]; axí guardat-vos-ne de retre per bé, mal» $\mathrm{Q}$ 243; "¿Per què·m retràs mal per bé?» Pi 303.

17. Traure mal loc. verb. DOLOR Patir, sofrir malestar. «Vol dir aytant que Nostre Senyor Déus que no permetria mal, si ell no fos bastant a traure'n» F 35 .

DER.: malfactor, malfaytor, malfeytor, malmetedor. CoMENT.: Amb el mateix sentit de traure mal hi ha maltraure 'patir, passar treballs' en l'Èxode del segle XIV, maltrer en Llull, i maltret 'esforç fatigós, treball dur' en Llull, Jaume I i en el Consolat de mar (AlcM).

\section{Abreviatures de les edicions dels sermons vicentins}

A = Sermons, volum primer, a cura de Josep Sanchis Sivera, Barcelona, Barcino, 1932.

$\mathrm{Ai}=$ Colección de sermones de Cuaresma y otros según el manuscrito de Ayora, a cura d'Adolfo Robles Sierra, València, Ajuntament, 1995.

$\mathrm{B}=$ Sermons, volum segon, a cura de Josep Sanchis Sivera, Barcelona, Barcino, 1934.

$\mathrm{Br}=$ «Le sermon en langue vulgaire prononcé a Toulouse par Saint Vincent Ferrier le Vendredi Saint 1416", Bibliothèque de l'École des Chartes, CXI, 1953, pp. 5-53.

$\mathrm{C}=$ Sermons, volum tercer, a cura de Gret Schib, Barcelona, Barcino, 1975.

$\mathrm{Ca}=$ San Vicente Ferrer en Castilla (1411-1412), a cura de Pedro María Cátedra, Salamanca, Consejería de Cultura y Turismo de la Junta de Castilla y León, 1994.

$\mathrm{Cc}=$ Sermones del Reial Col-legi i Seminari del Corpus Christi de València, a cura de Francisco M. Gimeno Blay \& M $^{a}$ Luz Mandingorra Llavata, València, Ajuntament, 2002.

$\mathrm{D}=$ Sermons, volum quart, a cura de Gret Schib, Barcelona, Barcino, 1977.

$\mathrm{E}=$ Sermons, volum cinqué, a cura de Gret Schib, Barcelona, Barcino, 1984.

$\mathrm{F}=$ Sermons, volum sisé, a cura de Gret Schib, Barcelona, Barcino, 1988, ms. 276, sermons núms. 181-207.

REVISTA VALENCIANA DE FILOLOGIA / I II (20I9) p. IO3-I 25

JORDI COLOMINA

La llengua dels sermons valencians de sant Vicent Ferrer / I 22 
$\mathrm{Fm}=$ «Sobre la 'traditio' de los sermones de San Vicente Ferrer. El de Valencia de 1410 acerca de la predestinación», a cura de Felip Mateu i Llopis, Boletín de la Sociedad Castellonenese de Cultura, XV, pp. 139-153.

$\mathrm{Fr}=$ Sermones de Cuaresma en Suiza (1404, [Friburg,] Couvent des Cordeliers, ms. 62), a cura de Francisco Gimeno Blay \& M. Luz Mandingorra Llavata, València, Ajuntament, 2009.

$\mathrm{G}=$ Fragmens del ms. 277, transcrits per Roc Chabàs (1903, i 16 sermons del ms. 277, transcrits per J. Sanchis Sivera, en Sermons, volum sisé, a cura de Gret Schib, Barcelona, Barcino, 1988, pp. 123-282.

$\mathrm{Ml}=\ll$ Del sermonario morellano de san Vicente. Secunda Dominica Adventus Domini. La Segona Lança», a cura de Manuel Betí, Boletín de la Sociedad Castellonense de Cultura, XI, 1955, pp. 126-136.

$\mathrm{Mp}=$ «Un sermón en valenciano de San Vicente Ferrer (De beato Petro)», a cura de Manuel Betí, Boletín de la Sociedad Castellonense de Cultura, III, 1922, pp. 123-133.

$\mathrm{P}=$ «Estudis i inventari de sermons de sant Vicent Ferrer» de Josep Perarnau, Arxiu de textos Catalans Antics, 18, 1999, pp. 9-811.

$\mathrm{Pa}=$ «Un sermó inèdit de sant Vicent: Attendite a falsis prophetis (Sermo in Dominica VIII post Trinitaten, Barcinone)», en Perarnau (1974).

Pc $=$ «La compilació de sermons de sant Vicent Ferrer de Barcelona, Biblioteca de Catalunya, ms. 477», a cura de Josep Perarnau, Arxiu de Textos Catalans Antics, IV, 1985, pp. 213-402.

Pe $=$ Sermonario de Perugia (Convento dei Domenicani, ms. 477), a cura de Francisco Gimeno Blay \& M. Luz Mandingorra Llavata, València, Ajuntament, 2006.

$\mathrm{Pi}=$ «Dos sermons incomplets del Divendres Sant», considerats com a d'autor desconegut per Perarnau, que els publica com a apèndix de «Els quatre sermons catalans de sant Vicent Ferrer en el manuscrit 476 de la Biblioteca de Catalunya», Arxiu de Textos Catalans Antics, XV, 1996, pp. 295-315. [Situats en el manuscrit un entre dos sermons vicentins i l'altre al final d'un altre, bé podrien ser de sant Vicent: per això els incloem com a material d'estudi.]

$\mathrm{Pp}=$ «Sermó inèdit de sant Vicent Ferrer explicant el 'Pare Nostre' (Barcelona, Biblioteca de Catalunya, ms. 477)», a cura de Josep Perarnau, Revista Catalana de Teologia, XIV, 1989, pp. 527-540.

$\mathrm{Pq}=\ll$ Els quatre sermons catalans de sant Vicent Ferrer en el manuscrit 476 de la Biblioteca de Catalunya", a cura de Josep Perarnau, Arxiu de Textos Catalans Antics, XV, 1996, pp. 109-340.

$\operatorname{Pr}=$ Procés de canonització de sant Vicent Ferrer, publicat en 1904 per Henri Dominique de Fages; traducció castellana de Sebastián Fuster Perelló, València, Ajuntament, 2007.

$\mathrm{Q}=$ Quaresma de sant Vicent Ferrer, predicada a València l'any 1413, a cura de Josep Sanchis Sivera, Barcelona, Institució Patxot, 1927.

REVISTA VALENCIANA DE FILOLOGIA / I I I (20I9) p. IO3-I 25

JORDi COLOMINA

La llengua dels sermons valencians de sant Vicent Ferrer / I 23 


\section{Bibliografia}

AlcM = A. M. Alcover \& F. de B. Moll, Diccionari català-valencià-balear, http//dcvb. iecat.net.

Betí, M. (1922) «Un sermón en valenciano de San Vicente Ferrer (De beato Petro)», Boletín de la Sociedad Castellonense de Cultura, III, pp. 123-133.

- (1955) «Del sermonario morellano de san Vicente: Secunda Dominica Adventus Domini; la Segona Lança», Boletín de la Sociedad Castellonense de Cultura, XI, pp. 126-136.

BRunel, C. (1953) «Le sermon en langue vulgaire prononcé a Toulouse par Saint Vincent Ferrier le Vendredi Saint 1416", Bibliothèque de l'École des Chartes, CXI, pp. 5-53.

Casanova, E. (2008) «La diversitat lingüística dels sermons de sant Vicent», en E. Casanova \& J. Buïgues (eds.), En el món de sant Vicent Ferrer, Teulada / València, Denes, pp. 27-50.

Cátedra, P. M. (1994) Sermón, sociedad y literatura en la Edad Media. San Vicente Ferrer en Castilla (1411-1412), estudio bibliográfico, literario y edición de textos inéditos, Salamanca, Consejería de Cultura y Turismo de la Junta de Castilla y León.

ChabÀs, R. (1903) Estudio sobre los sermones valencianos de San Vicente Ferrer, Madrid, Tipografía de la Revista de Archivos, Bibliotecas y Museos.

Fages, H. D. de (1904) Procès de la canonisation de Saint Vincent Ferrier pour faire suite a l'histoire du même saint, París / Lovaina.

- (1909) «Extraits de sermons catalans», en el seu llibre Oeuvres de Saint Vincent Ferrier, París, A. Icard.

ForNés, L. (2010) «Sant Vicent Ferrer en llengua llemosina», Paraula d'Oc. Fulls de recerca científica $i$ intuïció creativa, 11.

Fuster, J. (1955) «Notes per a un estudi de l'oratòria vicentina», Revista Valenciana de Filologia, IV, pp. 87-185; segona edició: «L'oratòria de sant Vicent Ferrer», en les seues Obres completes, 1. Llengua, literatura, història, Barcelona, Edicions 62, 1968, pp. 23-151.

Fuster Perelló, S. (2007) «Notícia preliminar» a la seua traducció del Proceso de Canonización de San Vicente Ferrer, València, Ajuntament, pp. 21-26.

Gimeno Blay, F. \& M. L. Mandingorra Llavata (presentadors i editors) (2002) San Vicente Ferrer, Sermones, ms. del Reial Col-legi-Seminari del Corpus Christi, València, Ajuntament.

- (2006) San Vicente Ferrer, Sermonario de Perugia (Convento dei Domenicani, ms. 477), València, Ajuntament.

- (2009) San Vicente Ferrer, Sermones de Cuaresma en Suiza (1404, Couvent des Cordeliers, ms. 62), València, Ajuntament.

Martínez Ferrando, J. E. (1952) El nostre sant Vicent Ferrer, València, Editorial Torre.

Mateu i Llopis, F. (1959) «Sobre la 'traditio' de los sermones de San Vicente Ferrer. El de Valencia de 1410 acerca de la predestinación», Boletín de la Sociedad Castellonense de Cultura, XV, pp. 139-153.

REVISTA VALENCIANA DE FILOLOGIA / II I (20I9) p. IO3-I 25

JoRdi COLOMINA

La llengua dels sermons valencians de sant Vicent Ferrer / I 24 
PDPF = Emil Levy, (1909) Petit Dictionnaire provençal-français, Heidelberg.

Perarnau i Espelt, J. (1974) «Sermones de sant Vicent Ferrer en los manuscritos de Barcelona, Biblioteca de Catalunya, 477 y Avignon, Musée Calvet, 610», Escritos del Vedat, IV, pp. 611-646.

- (1985) «La compilació de sermons de sant Vicent Ferrer de Barcelona, Biblioteca de Catalunya, ms. 477», Arxiu de Textos Catalans Antics, IV, pp. 213-402.

— (1989) «Sermó inèdit de sant Vicent Ferrer explicant el 'Pare Nostre' (Barcelona, Biblioteca de Catalunya, ms. 477) », en Revista Catalana de Teologia, XIV, pp. 527-540.

- (1996): «Els quatre sermons catalans de sant Vicent Ferrer en el manuscrit 476 de la Biblioteca de Catalunya», Arxiu de Textos Catalans Antics, XV, pp. 109-340.

- (1999): "Estudis i inventari de sermons de sant Vicent Ferrer», Arxiu de textos Catalans Antics, XVIII, pp. 9-811.

Riber, L. (1924) «Sant Vicent Ferrer», La Veu de Catalunya, 5 d'abril [citat per Fuster 1955a].

Riquer, M. de (1964) «Sant Vicent Ferrer», en la seua Història de la literatura catalana, II, Barcelona, Ariel, pp. 377-444; use la segona edició, Barcelona, Ariel, 1980, pp. 197-264.

Robles Sierra, A. (presentador i editor) (1995) San Vicente Ferrer, Colección de sermones de Cuaresma y otros según el manuscrito de Ayora, València, Ajuntament, pp. 13-40.

SAnchis Guarner, M. (1973) «Estudi preliminar» a sant Vicent Ferrer, Sermons de Quaresma, I, València, Albatros, pp. 7-35.

- (1980) «La llengua comuna i l'antihumanisme popular: sant Vicent Ferrer», en la seua Aproximació a la història de la llengua catalana. Barcelona, Salvat, pp. 203-210.

Sanchis Sivera, J. (1926) «Dos sermons de sant Vicent Ferrer», Boletín de la Real Academia de la Historia, LXIX, pp. 423-439; reeditats per Gret Schib en 1988 en el sisé volum dels sermons d' «Els Nostres Clàssics» de l'editorial Barcino, pp. 269-282.

- (1927) «Introducció» a la Quaresma de sant Vicent Ferrer, predicada a València l'any 1413, Barcelona, Institució Patxot, pp. IX-LVIII.

- (1932) «Notícia preliminar» a Sant Vicent Ferrer, Sermons, I, Barcelona, «Els Nostres Clàssics», pp. 9-16.

- (1935) Sermons de sant Vicent Ferrer, selecció, pròleg, bibliografia i notes, València, L'Estel.

Sснів, G. (1975) «Advertiment» a sant Vicent Ferrer, Sermons, III, Barcelona, Barcino, pp. 7-8. - (1976) «Els sermons de sant Vicent Ferrer», Actes del Tercer Col-loqui Internacional de Llengua i Literatura Catalanes (Cambridge, abril, 1973), Oxford / Barcelona, The Dolphin Book / Publicacions de l'Abadia de Montserrat, pp. 325-336.

- (1977) Vocabulari de sant Vicent Ferrer, Barcelona, Fundació Salvador Vives Casajuana.

Ysern, J.-A. (2010) «Vicent Ferrer», en Albert Hauf (dir.), Panorama crític de la literatura catalana. I. Edat Mitjana. Dels orígens a principis del segle xv, Barcelona, Vicens Vives, pp. 267-281.

REVISTA VALENCIANA DE FILOLOGIA / I I I (20I9) p. IO3-I 25

JORDi COLOMINA

La llengua dels sermons valencians de sant Vicent Ferrer / I 25 


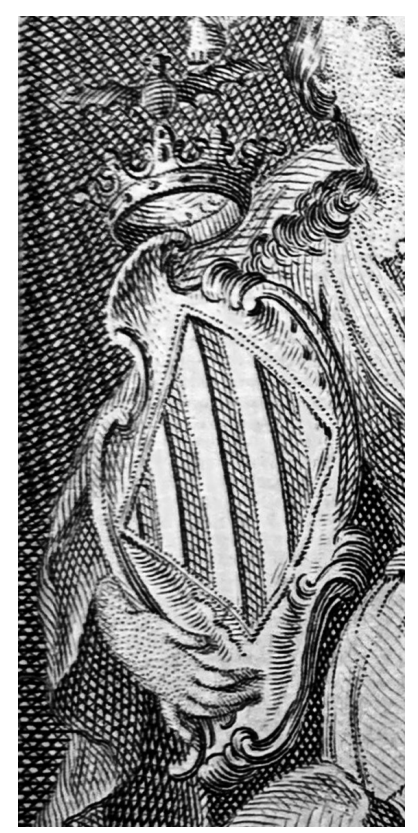

